\title{
Concepts for a geostationary-like polar missions
}

\author{
Malcolm Macdonald ${ }^{\mathrm{a}}$, Pamela Anderson ${ }^{\mathrm{a}}$, Laura Carrea ${ }^{\mathrm{b}}$, Benjamin Dobke ${ }^{\mathrm{c}}$, \\ Owen Embury ${ }^{\mathrm{b}}$, Chris Merchant ${ }^{\mathrm{b}}$, Paolo Bensi ${ }^{\mathrm{d}}$ \\ ${ }^{a}$ Strathclyde Space Institute, University of Strathclyde, Glasgow, Scotland; \\ ${ }^{\mathrm{b}}$ Department of Meteorology, University of Reading, Reading, England; \\ ${ }^{\mathrm{c}}$ Mission Systems Department, Earth Observation, Navigation and Science Directorate, \\ Airbus Defence \& Space, Stevenage, England; \\ ${ }^{\mathrm{d}}$ Earth Observation Mission and System Studies Section, Future Mission Division, \\ ESA-ESTEC, Noordwijk, Netherlands
}

\begin{abstract}
An evidence-led scientific case for development of a space-based polar remote sensing platform at geostationary-like (GEO-like) altitudes is developed through methods including a data user survey. Whilst a GEO platform provides a nearstatic perspective, multiple platforms are required to provide circumferential coverage. Systems for achieving GEO-like polar observation likewise require multiple platforms however the perspective is non-stationery. A key choice is between designs that provide complete polar view from a single platform at any given instant, and designs where this is obtained by compositing partial views from multiple sensors. Users foresee an increased challenge in extracting geophysical information from composite images and consider the use of non-composited images advantageous. Users also find the placement of apogee over the pole to be preferable to the alternative scenarios. Thus, a clear majority of data users find the "Taranis" orbit concept to be better than a critical inclination orbit, due to the improved perspective offered. The geophysical products that would benefit from a GEO-like polar platform are mainly estimated from radiances in the visible/near infrared and thermal parts of the electromagnetic spectrum, which is consistent with currently proven technologies from GEO. Based on the survey results, needs analysis, and current technology proven from GEO, scientific and observation requirements are developed along with two instrument concepts with eight and four channels, based on Flexible Combined Imager heritage. It is found that an operational system could, mostly likely, be deployed from an Ariane 5 ES to a 16-hour orbit, while a proof-of-concept system could be deployed from a Soyuz launch to the same orbit.
\end{abstract}

Keywords: Polar, Remote Sensing, Numerical weather prediction, Climate, Taranis

\section{INTRODUCTION}

The eighth annual 'Arctic Report Card' noted that "the effects of a persistent warming trend that began over 30 years ago remain clearly evident" and that this trend is influencing the Arctic's terrestrial and marine ecosystems [1]. The considerable change that has occurred in the Arctic, along with the concept of 'Arctic Amplification', and its largely anthropogenic origins is widely accepted. However, consensus remains elusive as to the impact of these changes within the cryosphere on northern mid-latitudes, the broader global climate, and the mechanism(s) which links them [2-7]. For example, in [7], it is suggested that reductions in sea-ice modify atmospheric circulation, with reduced upper-level zonal winds at high-latitudes causing increased amplification, resulting in stagnant weather patterns. However, the underlying mechanism for this linkage is not detailed and any link remains hypothetical. These uncertainties, along with the potentially global impact accentuate the current disparity between the breadth and depth of observations available for the tropics and mid-latitudes with the lack of geostationary-equivalent observations over the polar regions.

A geostationary-like polar observing system will radically improve key polar observations, including resolution of the diurnal cycle of phenomena related to, amongst other things, winds, clouds, sea ice, snow cover, and surface temperature

*malcolm.macdonald.102@strath.ac.uk; www.strath.ac.uk 
of sea, ice and land. Analysis of such phenomena will enable improved weather forecasting and modelling, along with environment modelling due to the high-quality continuous observations enabled. It will also significantly improve monitoring of 'Essential Climate Variables' (ECVs, see [8]), improving understanding of climate change and modelling of associated feedback processes.

Furthermore, rapid environmental change in the Artic is creating new commercial opportunities that in turn produce new pressures on the environment. A comprehensive polar observing system could enable monitoring of commercial activities and their environmental impact depending on the sensor technology employed. Summer ice melt is also creating new pressures on existing infrastructure. The Northwest Passage is becoming more accessible as a summer shipping route, which will in turn lead to a general increase in economic activity and growth in surface, air and marine traffic. As such, the current commercial Earth Observation market demand will spread to the poles, where currently it cannot be fully serviced.

This paper summarises an on-going study into mission concepts for geostationary-like polar observation systems. The paper develops an evidence-led scientific case for further development of a space-based polar remote sensing platform at geostationary-like altitudes. The scientific case considers the impact of observation from a highly elliptical orbit on meteorological and climatological requirements currently addressed from polar-orbiting instruments. In addition to consideration of well-known natural critical-inclination orbits (e.g., Molniya orbits), the paper presents and discusses the properties of "Taranis" orbits, which use low-thrust propulsion to maintain a Keplerian orbit away from the natural critical-inclination [9-13]. The paper addresses whether Taranis orbits add extra value relative to natural criticalinclination orbits.

\section{CONTEXT}

Satellite remote sensing is used in all the disciplines of polar science, including, meteorology, climate change, stratospheric chemistry, sea ice mapping, sea ice dynamics, monitoring of the great ice sheets, ocean ecosystem studies, and studies of the terrestrial biosphere. Some of the most advanced Earth remote sensing missions recently deployed are, in fact, dedicated to polar research (such as ICEsat and Cryosat-2).

A relatively recent survey on the use of remote sensing data for the polar region shows that more researchers using remote sensing identify themselves primarily as polar biologists in the context of climate change research, than identify themselves with physical science, such as sea ice, climate science, and meteorology (in decreasing order) [14]. The use of visible/infrared imagers is most common, with use of passive microwave and active microwave wave being the next most frequent. A surprising result is the use of scatterometers, which were not intended for polar research, but play a major role in Greenland Ice Sheet studies [15].

Presently, useful remote sensing of the polar regions is restricted to spacecraft in near-polar Low Earth Orbits (LEO), with altitudes up to $\sim 800 \mathrm{~km}$. LEO platforms provide high-spatial resolution polar observations. However, cloud cover is a major limitation for observations in the visible and infrared part of the spectrum when acquisitions are intermittent, as with LEO systems. This, coupled with the narrow instrument swath, results in low-temporal resolution polar surface coverage from LEO.

Platforms in Geostationary orbit (GEO), at a mean altitude of $35786 \mathrm{~km}$ over the equator, provide high-temporal resolution (e.g., 10 minutes). However, the view zenith angle (VZA) can be $\sim 65^{\circ}$ or more at latitudes poleward of $55^{\circ}$ north or south; see Figure 1. Many quantitative applications degrade rapidly at such VZAs, preventing the GEO configuration from giving sufficient observations beyond $\sim 55^{\circ}$ latitude. Furthermore, retrieval of certain geophysical properties are more challenging in polar regions. An important example is detection and classification of cloud cover over snow and ice surfaces, since both cloud tops and snow/ice surfaces are very bright at visible/near-IR wavelengths, and, they often have very similar temperatures as measured at mid-IR wavelengths due to frequent polar temperature inversions [16]. Discrimination in such "difficult" cases can be improved by exploiting the temporal domain for additional information [17]. 

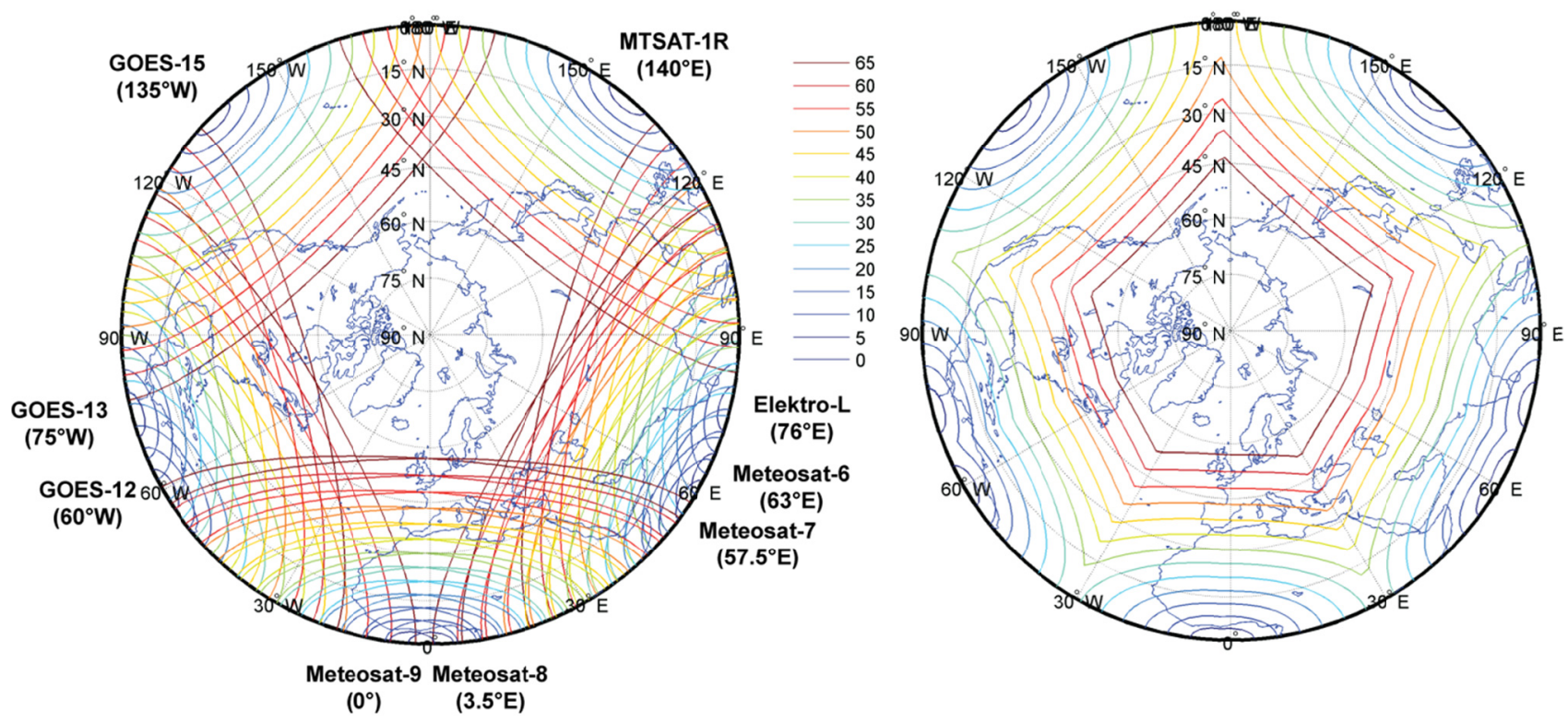

Figure 1. Polar stereographic plot of view zenith angle contours of nine spacecraft in geostationary orbit (contours show view angle measured in degrees); contour overlap on left and minimum view zenith angle on right.

\section{LITERATURE-BASED NEEDS ANALYSIS}

A number of remotely sensed variables are analysed from published sources in terms of the scientific and operational requirements, and the implied observation requirements to meet the scientific needs. Within the context and scope of this study, these are adequate to inform analysis of possible orbit and payload configurations, and are not intended to inform detailed sensor design.

Atmospheric Motion Vectors (AMVs) in near-real time are important for forecaster diagnostics of meteorological conditions and numerical weather prediction (NWP). Space derived AMVs can provide full wind field coverage in regions lacking conventional observations, for example, over the oceans, where in-situ wind observations are limited. Wind observations are particularly important for the initialization of numerical weather prediction (NWP) models [18]. From $70^{\circ}$ poleward, polar orbiting platforms do not provide full time continuity, although AMVs can be derived from overlaps of consecutive orbits. GEO observations have insufficient spatial resolution for cloud feature tracking in the latitudes from 60 to $70^{\circ}$; the resolution of GOES imagery is $\sim 12 \mathrm{~km}$ at $60^{\circ}$ latitude. This lack of observations is critical as the polar jet can often be found at these latitudes, and an accurate analysis of the strength and position of the polar jet is critical for numerical weather prediction (NWP) in the middle latitudes [19]. Solutions have been proposed to generate AMVs by compositing images from LEO and GEO [20]. However, compositing images generates latency and increases uncertainty associated with real-time tracking between the orbits of different platforms. The scientific and operational requirements are hourly of AMVs, requiring: consistent imaging of polar regions at intervals of $<30$ minutes, with a target interval of 10 minutes; spatial resolution across the full polar disk of $5 \mathrm{~km}$ at the sub-satellite point, with a target of $<2 \mathrm{~km}$; the region poleward of $55^{\circ}$ (hereafter the "full polar disk") to be imaged at view zenith angles of $<60^{\circ}$; and, reflectance and infra-red imagery to support cloud-ice-water discrimination and cloud-top-temperature estimation (for height assignment).

Ice properties of the polar region such as sea-ice area, extent and concentration, ice thickness, ice drift, ice snow albedo, ice type classification, ice roughness and deformation and icebergs in the Arctic are of specific interest in the polar regions. In regards to sea-ice parameters, current remote sensing relies heavily on microwave remote sensing from LEO, both passive and active, which is not demonstrated from GEO orbits. Use of microwaves allows reliable surface 
observation irrespective of cloud cover [21]. An optical/IR mission from GEO-like orbits above polar regions would afford additional opportunity mainly due to the high temporal resolution, permitting surface observation between clouds. However, assuming the continuity of polar-orbiting microwave sensors, most sea-ice parameters will continue to be measured principally from these. An area where the increased surface coverage (between clouds) from an optical/IR mission in GEO-like orbit may contribute significantly is observing sea-ice/land-ice/snow albedo. Albedo observation is relevant to the regional radiation balance and key to monitoring of both the state of sea-ice melt ponds in summer, and the supra-glacial lakes (e.g. over Greenland, revealed via their albedo changes). The melt-pond status of sea-ice in early summer is highly predictive of the maximum degree of summer melt [22]. The scientific and operational requirements are: the full polar disk imaged at intervals of $\leq 30$ minutes to benefit from moving clear-sky areas between cloud fields; spatial resolution across the full polar disk of $\leq 5 \mathrm{~km}$ for general albedo observation (for monitoring of supra-glacial lakes $\leq 1 \mathrm{~km}$ is required); and, the full polar disk imaged at view zenith angles of $<60^{\circ}$. It is speculated to be advantageous to albedo estimation for the view zenith and azimuth angles to change in time rather than be completely static, implying that GEO-like orbits (where this is the case) may be better than a static observational geometry (as with GEO).

Sea surface temperature (SST) is retrieved from GEO and LEO instruments with relatively low uncertainty ( 0.4 K) globally $[23,24]$. In the polar region, these are retrieved from polar orbiting satellites, offering a daily average. However, the accuracy of polar-region SSTs is poorer than elsewhere, and varies seasonally [25]. There is a diurnal cycle in SST in polar summer, which can be significant, as at other latitudes, i.e., up to $3 \mathrm{~K}$ in amplitude under low wind conditions, responding to the solar elevation even when daylight is continuous [26]. Combining diurnal and other short-timescale variability with the non-continuity of observation from individual platforms, and with inter-sensor biases, progress in developing more accurate SSTs in polar regions has been challenging. GEO-like observations would significantly support improvement in SST accuracy by: allowing the diurnal cycle under clear-sky conditions to be directly observed over complete days from a single sensor; providing multi-sensor matches with polar orbiters to help characterise and correct their inter-sensor SST biases; increasing the IR coverage by maximising the surface seen through gaps between the (often extensive) polar cloud cover. The scientific and operational requirements are: the full polar disk imaged at intervals of $<30$ minutes to benefit from moving clear-sky areas between cloud fields; spatial resolution across the full polar disk of $5 \mathrm{~km}(\sim 2 \mathrm{~km}$, at the sub-satellite point), to resolve gaps between cloud cover and SST gradients, particular near the marginal ice zones; the full polar disk imaged at view zenith angles of $<60^{\circ}$ (SST accuracy decreases rapidly at higher angles because atmospheric effects increasingly mask surface temperature variations); and, brightness temperature random (noise) and systematic (bias) uncertainty less than $0.15 \mathrm{~K}$ and $0.1 \mathrm{~K}$ respectively (1 sigma).

Land surface temperature (LST) is measured using the thermal infrared part of the spectrum from LEO and GEO. Instrument swaths from LEO progressively overlap at increasing latitudes, thus at high latitudes many ground surface observations are available each day. However, the swath overlap of near polar orbiting satellites over sub-polar regions is often insufficient to construct diurnal temperature curves because of cloud cover [27]. Space-derived high-latitude LST is scientifically highly relevant to, for example, ice mass balance over the Greenland ice sheet, and monitoring and understanding changes in tundra and permafrost regions, with impacts on high-Arctic ecosystems and greenhouse gas release from changing soils. The scientific and operational requirements repeat those for SST.

Precipitation is usually estimated through active and passive microwave instruments (radar and radiometer) on LEO platforms. These technologies not being presently demonstrated from GEO orbits, hence no requirements for GEO-like polar orbits for precipitation are developed.

Aerosol and cloud properties products, such as aerosol optical depth (AOD), are retrieved from LEO (Moderate Resolution Imaging Spectroradiometer, MODIS, instrument) and GEO (Spinning Enhanced Visible and Infrared Imager, SEVIRI, instrument) platforms. The spatial and temporal resolutions of these aerosol products are $10 \mathrm{~km}$ and two measurements per day for MODIS, and $\sim 25 \mathrm{~km}$ and observation intervals of 15 minutes for SEVIRI. Retrievals of AOD and shortwave radiation budget from GEO has significant heritage [28]. Aerosol information such as the AOD is challenging to retrieve at high latitudes from LEO platforms due to the high reflectance of snow and ice surfaces, and additional problems associated with large solar zenith angles [29]. Therefore, aerosol remote sensing has not been widely used in the Arctic region [30]. The scientific and operational requirements are: aerosol optical depth and aerosol class above all surfaces (water, ice land and snow); full polar disk imaged at intervals of $<30$ minutes to benefit from moving clear-sky areas between cloud fields, and possibly exploit progression in solar geometry; spatial resolution of image across the full polar disk of $\leq 5 \mathrm{~km}$ (giving capability comparable to GEO products); and, full polar disk imaged at view zenith angles of $<60^{\circ}$. 
Surface solar irradiance (SSI) is measured in the visible and near infrared part of the spectrum; with the amount of solar radiation reaching different parts of the Earth a principal driver of global and regional climate. Instruments on GEO platforms provide observations at high temporal resolution (i.e. 15 minutes), with a spatial resolution between $3-5 \mathrm{~km}$. SSI in combination with surface albedo is scientifically important for surface energy balance, including summer surface melt of ice and snow, sea-ice dynamics during the melt-pond season, supra-glacial lakes, and the energetics of tundra and permafrost zones. The measurement principle is generally to modulate calculated top of atmosphere insolation in the light of the reflectance and inferred optical thickness of clouds in the field of view. Because the cloud field may evolve rapidly compared to the solar geometry, resolving its evolution is the main driver for temporal resolution. Highly accurate SSI products have been derived from the 15 minute imagery from SEVIRI. The scientific and operational requirements are: the full polar disk imaged at intervals of $\leq 15$ minutes to give good SSI accuracy for each location; spatial resolution across the full polar disk of $\leq 5 \mathrm{~km}$, giving capability comparable to GEO products; and, full polar disk imaged at view zenith angles of $<60^{\circ}$.

Tropospheric humidity, and/or radiances sensitivity to tropospheric humidity, is required for NWP, with remotely sensed humidity particularly important in regions of limited density of radio-soundings, including polar regions. As the required sounding and spectrally resolved technologies have not been demonstrated from GEO, requirements for GEO-like polar orbit are not formulated here. However, free tropospheric humidity has been retrieved from GEO platforms using infrared observations from SEVIRI [31]. The radiance in one or more "tropospheric water vapour channels" (e.g. at $6.2 \mu \mathrm{m}$ ) is well established for meteorological diagnostics (nowcasting), mid/upper tropospheric humidity estimation, and for atmospheric motion vectors for the upper troposphere from tracking of humidity features. As these are smoother than the cloud feature field, coarser spatio-temporal resolution is adequate compared to cloud-feature AMVs. Humidity based AMVs are complementary to those based on clouds in that track-able features are generally found at different locations, and apply often to different levels in the atmosphere. The requirements are formulated to support interpretation of upper/mid tropospheric humidity and humidity-based AMVs. The scientific and operational requirements are: observation of mid/upper tropospheric humidity at "water vapour" thermal wavelengths across the full polar disk; full polar disk imaged at intervals of $\leq 1$ hour at wavelengths sensitive to mid- and/or upper tropospheric humidity, using channels optimised for high latitude atmospheric profiles (perhaps around $6.2 \mu \mathrm{m}$ ); spatial resolution of image across the full polar disk of $\leq 5 \mathrm{~km}$, giving capability comparable to GEO products; and, full polar disk imaged at view zenith angles of $<60^{\circ}$.

Downward longwave radiation (DLI) affects the surface energy balance, and is important for meteorology particularly in relation to the rate of surface cooling at night, development of fogs, et cetera. The drivers of variability of DLI are the atmospheric temperature profile, atmospheric humidity profile and the temperature of the lowest cloud base. Over decadal time scales, DLI is modulated by secular trends in greenhouse gases and atmospheric temperature. Although DLI estimates are developed from SEVIRI, these are less accurate than SSI. Higher accuracy DLI estimates can be gained through the use of active sensing, however such instrumentation is not presently demonstrated from GEO. Thus, requirements for GEO-like polar orbits are not developed herein, with observation requirements for SSI and tropospheric humidity covering the required capability to use a SEVIRI-like imager for DLI estimation.

Ocean surface vectors wind (OSVW) are crucial to understand and predict the short and longer-term processes that drive the environment. OSVW is measured with active microwave scatterometers on LEO platforms, with passive microwave radiometers measuring wind speed [32]. However, requirements for OSVW are not fully met by available measurements, principally due to the available temporal resolution. Scatterometry or passive radiometry from GEO would in principle offer a suitable temporal resolution if the retrieval problem for the viewing geometry is solvable. However, the power and antenna size requirements for such a system in GEO would remain a challenge. Thus, requirements for GEO-like polar orbits are not developed herein.

Other areas of interest include active fire products and ocean colour. 


\section{USER SURVEY}

A survey to assess the requirements for and applications of GEO-like observations at polar latitudes was conducted by gathering input from potential data users. The questions addressed in the survey were:

- whether a GEO-like coverage for polar regions would offer significant improvement compared to the current capability offered by the constellations of LEO and GEO platforms;

- how significant is the improvement that the new Taranis orbit offers compared to the potential of the Molniya orbit to give geostationary-like coverage;

- developing an understanding of the user's needs for polar observations;

- if the composition of images to gain a single image of the full polar disk would create insurmountable problems.

The survey consisted of four parts:

- information about the participants' applications;

- their interest on GEO-like radiances/products of the polar regions;

- their impression on the Taranis orbit and their requirements for the observations from the satellite on the orbit;

- their opinion on a comparison between Molniya and Taranis orbit.

The survey attracted 80 participants, predominantly from North America and Europe, with a significant majority of participants from countries with territory north of $55^{\circ}$ latitude. Latitudes of interest are mainly the north of $55^{\circ} \mathrm{N}$ or both north of $55^{\circ} \mathrm{N}$ and south of $55^{\circ} \mathrm{S}$; few participants were interested only in latitudes south of $55^{\circ} \mathrm{S}$. The majority of participants $(70 \%)$ were not current users of observations or products from GEO platforms. This presumably reflects the fact that many participants in the survey were correctly targeted as being interested in polar regions, and the relevance of GEO observations for such regions is limited. Other participants have global interest, which of course includes interest in polar regions.

Most of the participants (87\%) stated they would or possibly would benefit from observations or products currently not available. The type of products or observations desired were mainly in the visible and IR, with requirements for observations with higher spatial resolution $(\sim 1 \mathrm{~km})$ that also sample the diurnal cycle. The four most requested products from a GEO-like polar platform were: sea-ice concentration; sea surface temperature; ice surface temperature; and, land surface temperature. Similarly, for ice surface temperature, land surface temperature, precipitation, atmospheric motion vectors, active fire products and cloud properties, the availability of such products from a GEO-like polar platform would lead to adoption of these products by some users who do not currently use them from GEO platforms. However, an interesting aspect of the survey is that participants in general do not describe themselves as having a single area of application and generally do use multiple products. It was therefore not possible to link the products they would like to use from GEO-like orbits to specific application domains. The reality is that real scientific problems often span several nominal application domains and could be informed by multiple types of products.

\subsection{Taranis Orbit}

Participants were presented with two mission configurations:

1. The full polar disk is imaged (at VZA of $<60^{\circ}$ ) by a single platform, which is one of three on co-planar 12 hour orbits of maximum altitude $40,170 \mathrm{~km}^{\dagger}$

2. The full polar disk is imaged (at VZA of $<60^{\circ}$ ) by either a single spacecraft ( $\sim 83 \%$ of the time), or by a composited view from two platforms $(\sim 17 \%$ of the time), both on the same orbit as scenario 1.

For scenario 1, the spacecraft are equally spaced around the orbit and each $1 / 3$ of an orbit a spacecraft exits the observation window and another enters, both viewing the polar region with the same, but rotated $180^{\circ}$, VZA distribution, as shown in Figure 2; this is the handover point between platforms.

\footnotetext{
${ }^{\dagger}$ A detailed description of this configurations can be found at http://youtu.be/Dr-j-6RYFGA

* A detailed description of this configurations can be found at http://youtu.be/s4RgTUnmZ1o
} 
a)

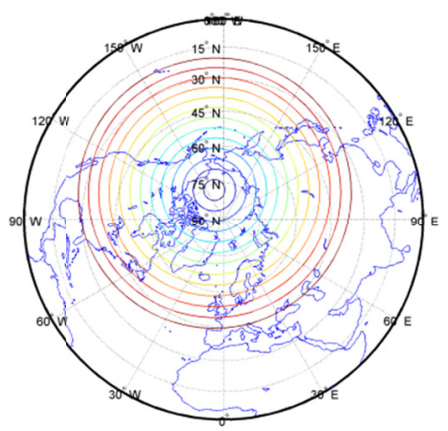

b)

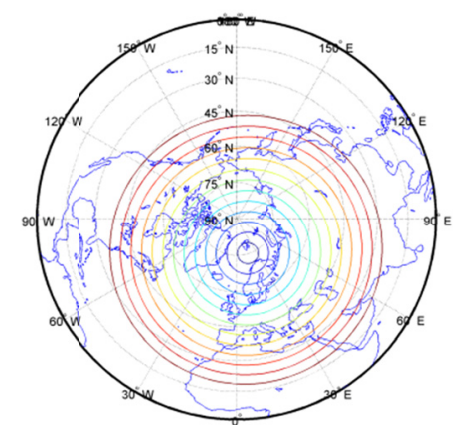

c)

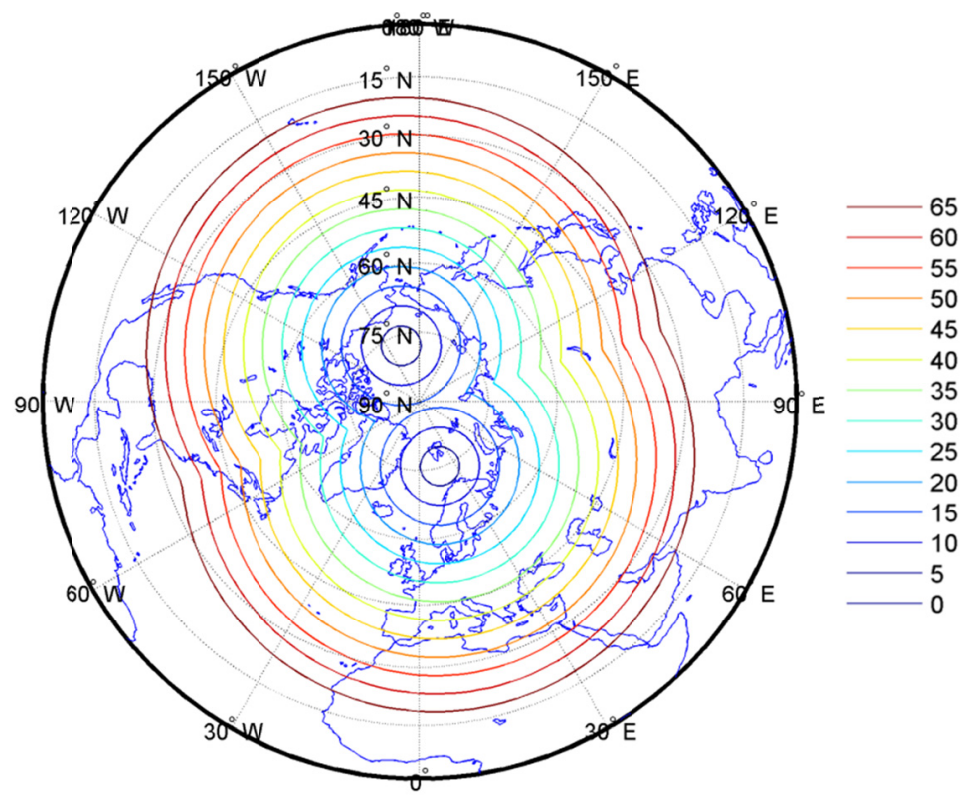

Figure 2. VZA maps at handover in scenario 1; individual spacecraft in a) and b), and a composited VZA map in c). VZA contours are in degrees.

For scenario 2 , the two spacecraft are equally spaced around the orbit, observing the polar region for $3 \frac{1}{2}$ hours either side of apogee passage. Hence, when one spacecraft is above the North Pole the other is above the South Pole, after $2 \frac{1}{2}$ hours the spacecraft that was above the North Pole no longer has sufficient vantage to observe the full polar disk at VZA of $<60^{\circ}$, and hence the spacecraft that was above the South Pole is required to complement the observations. For the next hour the two spacecraft must operate as a pair until the spacecraft that was initially above the South Pole can view the full polar disk at VZA of $<60^{\circ}$, at which point the spacecraft that was initially above the North Pole concludes its observation campaign for that orbit. Following a further $2 \frac{1}{2}$ hours, the spacecraft will be over the opposite pole to which they started and the pattern repeats for the second half of the 12-hour orbit. Note that the ground track will repeat after two orbits, that is, one sidereal day, or approximately 24 hours. This scenario is illustrated further in Table 1.

Survey participants were more confident in the usefulness of the non-composited scenario 1 than scenario 2, which requires compositing; $63 \%$ of participants did not foresee a problem with scenario 1 , while only $45 \%$ were as confident in scenario 2, and those foreseeing a potential problem increased from $33 \%$ to $45 \%$. Note further that a clear majority of participants $(98 \%)$ found the placement of apogee over the pole to be useful $(60 \%)$ or potentially useful $(38 \%)$.

As a platforms moves through the observation window around apogee a continuous evolution of the VZA/pixel area occurs. Few survey participants $(6 \%)$ found the continuous evolution of the VZA an insurmountable problem, while the majority $(74 \%)$ felt the observations would be useable without difficulty or through modifications to current algorithms that they felt 'would probably be successful'. Similarly, a discontinuity in the VZA/pixel area is present between each period of observation. Again, few survey participants $(6 \%)$ found this to be an insurmountable problem. The crosscalibration of the sensors was important for the majority of participants.

Figure 3 shows the best and worst case VZA maps from a Molniya orbit, using three spacecraft on three orbit planes. It is found that to image the full polar disk at VZA of $<60^{\circ}$ composited images are required, as shown in Figure 3c, making this three spacecraft scenario equivalent to the two spacecraft Taranis orbit scenario. The majority of participants $(87 \%)$ found the Taranis orbit to be either 'much better' $(57 \%)$ or 'marginally better' $(30 \%)$, with the remainder not seeing any advantage. No participants thought the Taranis orbit would be disadvantageous. Figure 4 details the responses comparing Taranis and Molniya orbits' usefulness across the domains of application of those users who make direct use of radiances. Note that a single participant can be involved in more than one domain, and not all the participants are direct users of radiances. The majority of users of radiances find the Taranis orbit preferable, with participants involved in 
Table 1. VZA maps at two handovers in scenario 2. VZA contours are in degrees; see Figure 2 for legend.

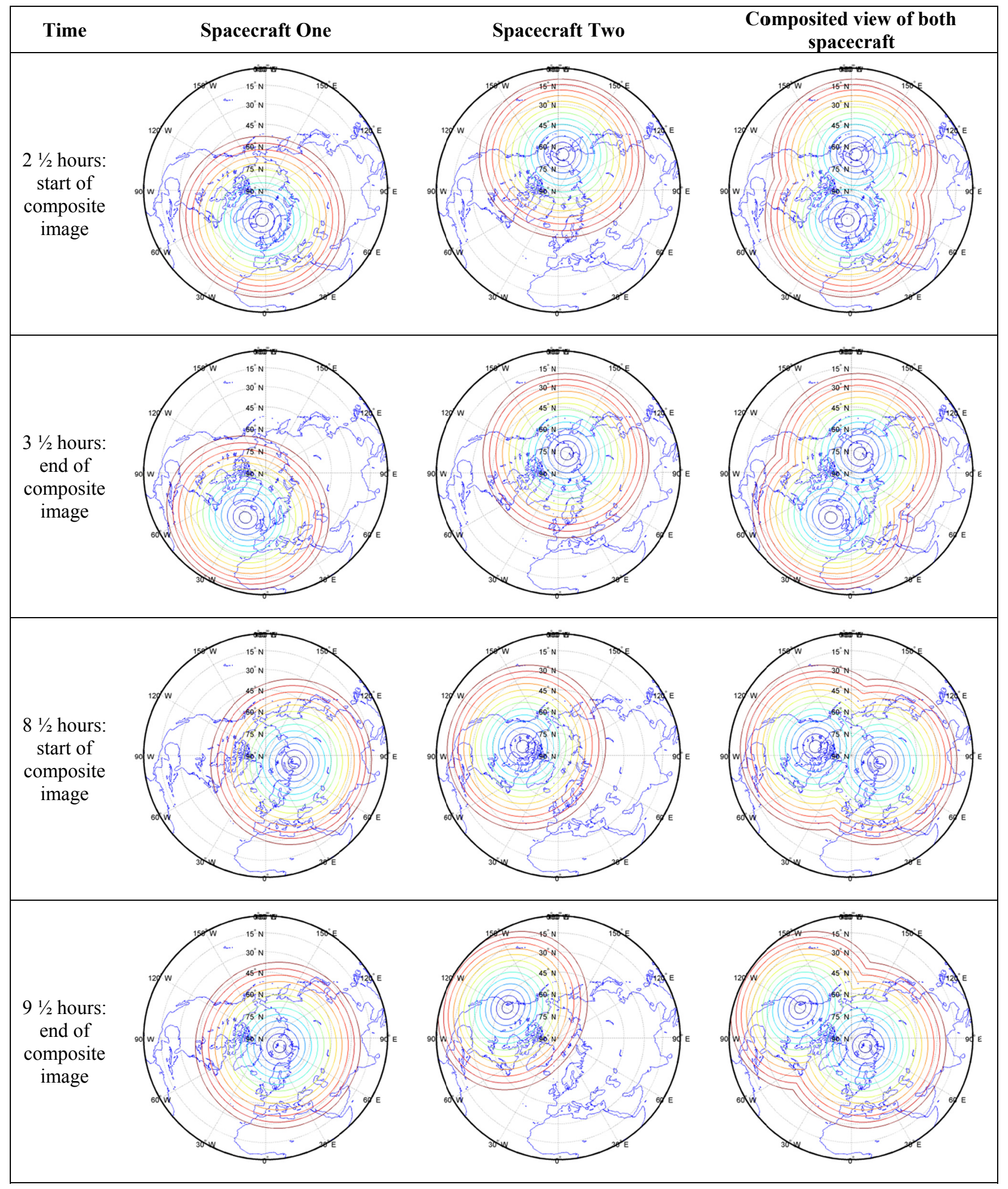


a)

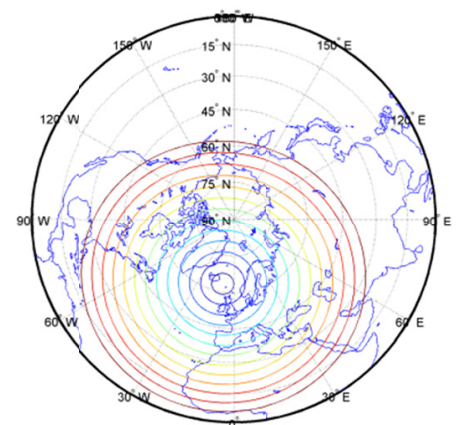

b)

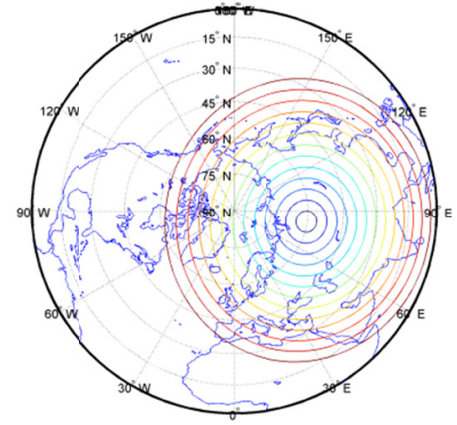

c)

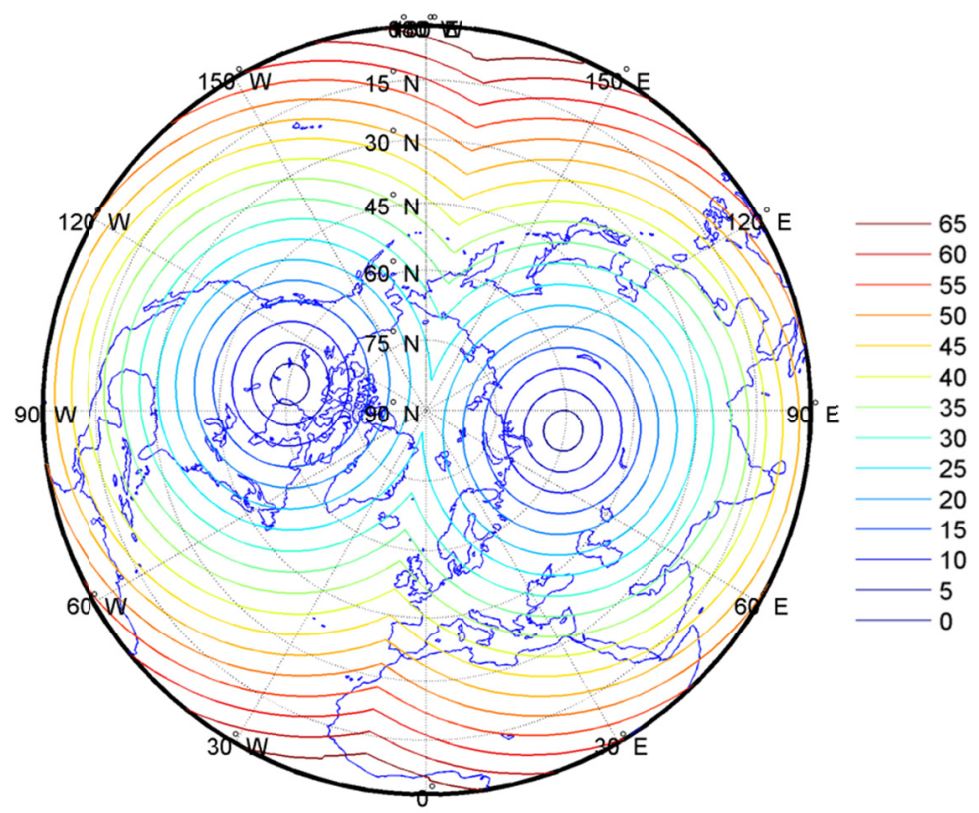

Figure 3. VZA maps of a) best and b) worst case Molniya orbit observations, and a composited VZA map in c) of two spacecraft at worst case. VZA contours are in degrees.

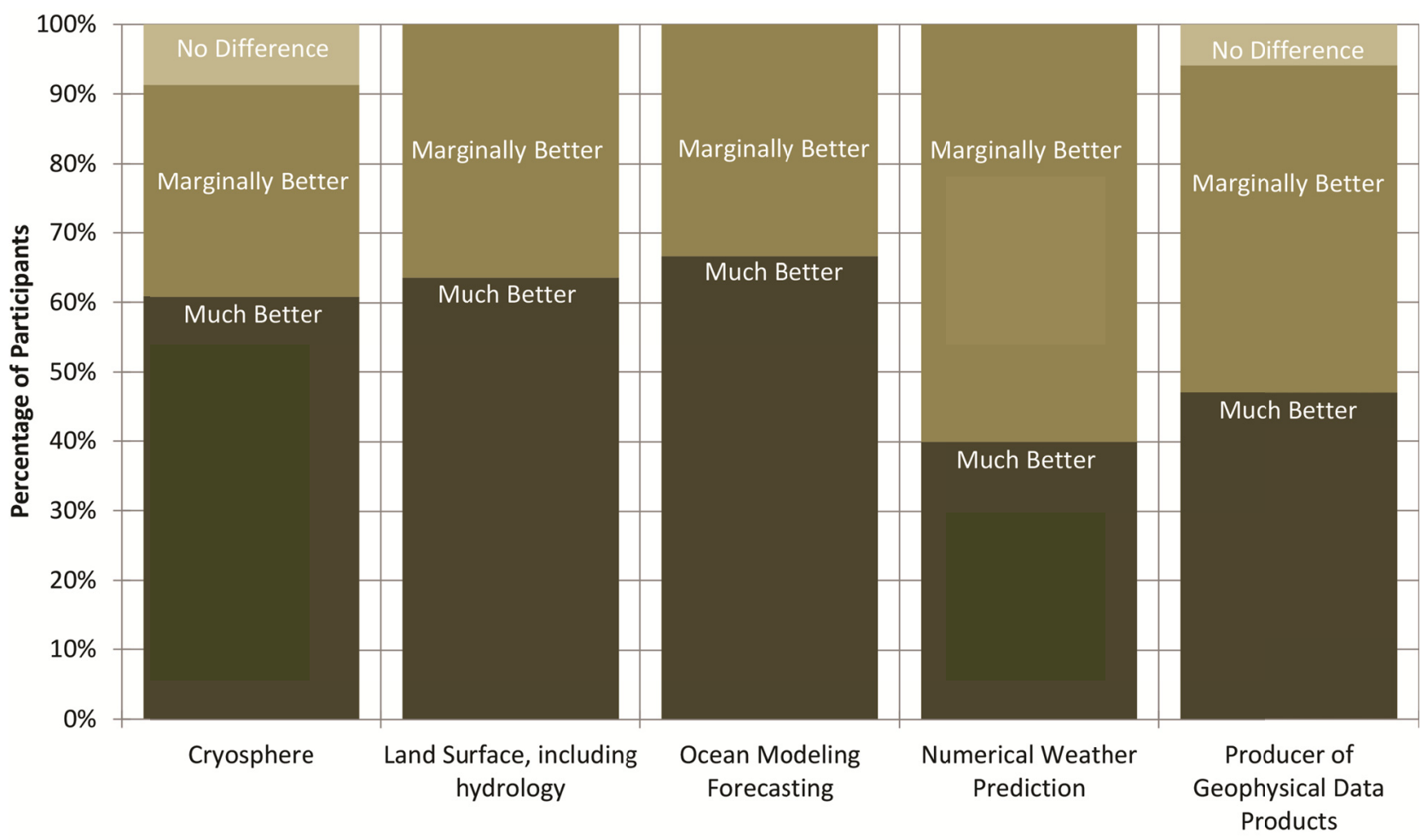

Figure 4. Analysis of users of radiances' preference between Taranis and Molniya orbit 
NWP and producers of geophysical data slightly less likely to consider the Taranis orbit 'much better' than Molniya than those in other domains.

Of the participants who find the Taranis orbit better or marginally better, $27 \%$ think that the improvements offered are definitely significant for their application and $51 \%$ think that the improvements are marginally better. Relatively few see no advantage. The most popular contexts are the cryosphere and producers of geophysical data, and the majority of categories are of the view there would be a marginal improvement offered by a Taranis system relative to a Molniya system.

\section{SCIENTIFIC AND OBSERVATION REQUIREMENTS}

The main objectives of a GEO-like polar system could be focussed on the cryosphere, geophysical data products and NWP at polar and sub-polar regions. The relevant observations are radiances in the visible/near infrared and the thermal part of the spectrum. Cloud cover is a particular limitation for observations in this part of the spectrum, as discussed in [33], and high temporal resolution measurement improves the coverage issues.

Based on the survey results, needs analysis, and current remote sensing techniques proven from GEO, the user scientific objectives are focussed on monitoring the polar and sub-polar regions with time continuity using a visible and infrared imager. The scientific requirements are shown in Table 2, with a consolidated set of observation requirements supporting these shown in Table 3. Note that the system is, for brevity, described as a "GEO-like polar system", although the latitude range covered at reasonable VZA, in order to be complementary to the GEO system, includes sub-polar latitudes (poleward of $55^{\circ}$ ).

\section{ORBIT ANALYSIS}

Three potential orbit configurations are shown in Figure 5, each capable of observing the full polar disk with a VZA of $<60^{\circ}$ but offering different advantages. The orbits configuration scenarios shown in Figure 5 are,

- three spacecraft on 10 hour, $2000 \times 32400 \mathrm{~km}$ altitude, high-radiation orbit, no de-orbit required at End-of-Life (EoL);

- three spacecraft on 12 hour, 300 x $40170 \mathrm{~km}$ altitude, high-radiation orbit, requires EoL de-orbit; and,

- four spacecraft on 16 hour, 10000 x $41740 \mathrm{~km}$ altitude, low-radiation orbit, requires EoL de-orbit.

As discussed in Section 4.1 the number of required spacecraft can be reduced by one if data products are retrieved using composited images. However, by not requiring the use of composited images an operational GEO-like polar system achieves graceful degradation in the event of the loss of a spacecraft.

Table 2. Scientific requirements

\begin{tabular}{|ll|}
\hline Number & Requirement \\
\hline SR-1 & $\begin{array}{l}\text { Satellite-derived Atmospheric Wind Vectors from cloud-feature tracking available over the } \\
\text { full polar disk with at least hourly temporal resolution. }\end{array}$ \\
\hline SR-2 & Satellite-derived surface albedo of ice and snow surfaces with at least monthly resolution. \\
\hline SR-3 & $\begin{array}{l}\text { Satellite-derived sea surface temperature, land surface temperature and ice surface } \\
\text { temperature with at least hourly resolution under clear skies. }\end{array}$ \\
\hline SR-4 & $\begin{array}{l}\text { Satellite-derived aerosol optical depth and aerosol class above all surfaces (water, ice land and } \\
\text { snow). }\end{array}$ \\
\hline SR-5 & $\begin{array}{l}\text { Satellite-derived surface solar irradiance derived from reflectance imagery with at least 15 } \\
\text { minute sampling (to match the accuracy available from SEVIRI). }\end{array}$ \\
\hline SR-6 & $\begin{array}{l}\text { Observation of mid/upper tropospheric humidity at "water vapour" thermal wavelengths } \\
\text { across the target region, suitable also for supporting humidity-based AMVs. }\end{array}$ \\
\hline SR-7 & $\begin{array}{l}\text { Simultaneous image acquisition with significant overlap of coverage around the times of } \\
\text { handover between prime platforms, to support rigorous inter-calibration and applications } \\
\text { benefiting from "dual view". }\end{array}$ \\
\hline
\end{tabular}


Table 3. Observation requirements

\begin{tabular}{|ll|}
\hline Number & Requirement \\
\hline OR-1 & Reflectance and infra-red imagery across target region at wavelengths suitable to support \\
& $\bullet \quad$ cloud-ice-water discrimination, \\
& $-\quad$ cloud-top-temperature estimation for height assignment, \\
& $-\quad$ aerosol optical depth estimation, \\
& $-\quad$ mid/upper tropospheric humidity estimation, \\
& - $\quad$ surface temperature estimation, \\
\hline OR-2 & Full polar disk (meaning, latitude poleward of $55^{\circ}$ ) imaged at intervals of 15 minutes. \\
\hline OR-3 & Full polar disk imaged at view zenith angles of $<60^{\circ}$. \\
\hline OR-4 & Continuity of image geometry between all consecutive image pairs (except at "hand-over") \\
\hline OR-5 & must be adequate to support cross-correlation of features. \\
& Brightness temperature uncertainty for thermal channels: random (noise) and systematic (bias) \\
\hline OR-6 & uncertainty less than $0.15 \mathrm{~K}$ and $0.1 \mathrm{~K}$ respectively $(1 \sigma)$. \\
\hline
\end{tabular}

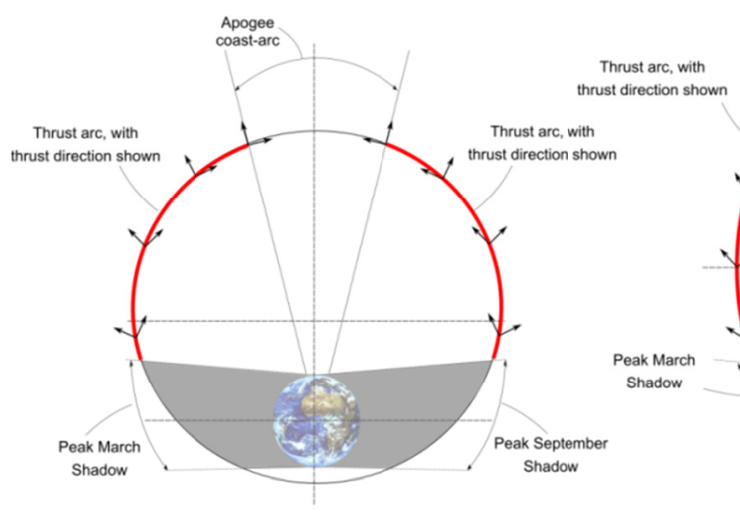

a)

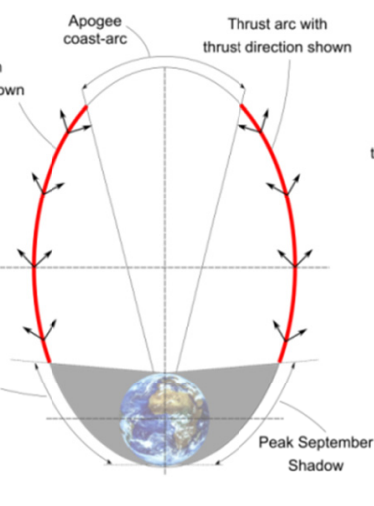

b)

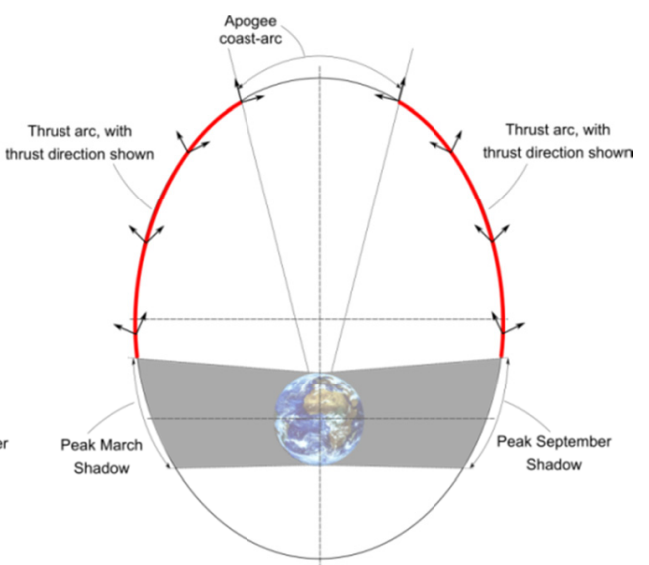

c)

Figure 5. Three possible orbit configurations including shadow and thrust arcs: a) three spacecraft on 10 hour orbit period; b) three spacecraft on 12 hour orbit period; c) four spacecraft on 16 hour orbit period. Thrust arcs shown are maximum extent of trajectory when low-thrust propulsion system can operate to avoid shadow and observation regions of orbit, the two arrows give the direction of thrust for the two thrusters per spacecraft.

\section{INSTRUMENT CONCEPT}

Considering the objectives of a GEO-like polar platform, and the science and observation requirements (Tables 2 and 3 ) the instrument concept is based on heritage from the Flexible Combined Imager (FCI) instrument, under development for the Meteosat Third Generation platforms. Table 4 lists the eight wavelengths considered, four in each of the visible and near-infrared range and the infrared range, and gives an indicative of the relationship between these and the desired level 2 data products.

Two instrument concepts are currently considered. In both, mass savings are achieved from the FCI by reducing the mass of the instrument baseplate, by reducing the cryo-coolers, due to the reduced number of IR channels relative to FCI, and reduction in the spatial resolution from $1 \mathrm{~km}$ to $2 \mathrm{~km}$. Note that the spatial resolution can be reduced whilst still satisfying the observation requirements arrived at in this study, and results in an overall reduction in support housing structure, due to the reduced focal length; a spatial resolution of $2 \mathrm{~km}$ is consistent with the Meteosat Second 
Generation's SEVIRI. In the first instrument concept all eight wavelengths in Table 4 are considered, while the second eliminates the IR channels to gain further mass savings by removing the cold-optics, resulting in non-compliance with OR-1 and OR-6.

Table 5 presents an approximate mass budget for the two instrument concepts, showing that these instruments, including a $20 \%$ mass margin, have a nominal mass requirement of $251 \mathrm{~kg}$ and $200 \mathrm{~kg}$. To gain further mass reductions would require a movement away from FCI heritage, the further reduction of spatial resolution, and/or the use of lightweight technologies.

The thermal loading of the instrument was considered under solar maximum conditions using the 'Thermal and Orbital Propagated Information Calculator' or TOPIC tool (TOPIC is based on ARTIFIS and is therefore ESARAD compatible) [34]. As expected, the thermal loadings on the spacecraft are dominated by the solar flux due to apogee-dwell. Perigee is a relatively short period of the orbit and the Earthshine and Albedo are smaller contributions to the total loading. The total combined magnitude of the flux is in the region of $2000 \mathrm{~W}$ on all surfaces. This loading is similar to that expected on a GEO spacecraft per square meter and is not seen as a critical driver for the spacecraft design. It was found however that during certain periods, particularly for the winter solstice case, the Nadir surface of the spacecraft, onto which the instrument(s) would be mounted, has a significant thermal flux. Hence, during these periods incident flux (that is, stray light) is likely to enter the instrument and baffling will need to be designed in-order to mitigate this.

Table 4. Indication of relationship between instrument spectral channels and level 2 products.

\begin{tabular}{|l|l|l|l|l|l|l|l|l|}
\hline & & & & & & & \\
\hline
\end{tabular}

Table 5. Instrument concept approximate mass budget.

\begin{tabular}{|c|c|c|}
\hline Sub-System & $\begin{array}{c}\text { Option 1: VIS/NIR \& IR wavelengths } \\
\text { (kg) }\end{array}$ & $\begin{array}{c}\text { Option 2: VIS/NIR wavelengths } \\
\text { (kg) }\end{array}$ \\
\hline Scan assembly & 24 & 24 \\
\hline Telescope assembly & 35 & 35 \\
\hline Focal plane assembly & 6 & 2 \\
\hline Calibration unit & 4 & 4 \\
\hline Cooling System & 22 & 0 \\
\hline Main structure & 28 & 28 \\
\hline Main baffle & 19 & 19 \\
\hline Housing & 16 & 16 \\
\hline Electronics & 55 & 39 \\
\hline Current best estimate mass & 209 & 167 \\
\hline Sub-System mass margin $(20 \%)$ & 42 & 33 \\
\hline Nominal Mass & 251 & 200 \\
\hline
\end{tabular}


The radiation environment of the instrument was considered for the three different orbit concepts introduced in Figure 5. For the 10 and 12 hour orbits, non-radiation hard electronics would require around $3 \mathrm{~mm}$ of aluminium shielding, for a five year mission assuming no self-shielding by the spacecraft. For the 16 hour orbit, this reduces to $0.5 \mathrm{~mm}$, a mass factor reduction of six. For rad-hard components, the 10 and 12 hour orbit would require approximately $1 \mathrm{~mm}$ of aluminium shielding, and the 16 hour orbit none. Assuming a typical $50 \mathrm{~cm}$ per side instrument electronics box the additional shielding required for non-rad hard parts ranges from $2-12 \mathrm{~kg}$, and from $0-4 \mathrm{~kg}$ from rad-hard parts; an increase in instrument mass of up to $5-7 \%$, including a $20 \%$ sub-system mass margin.

\section{8. $\quad$ SYSTEM ANALYSIS}

The orbits considered in Figure 5 are 'non-standard', therefore launcher user manuals do not detail the mass that can be delivered to these orbits. Analysis was conducted using vehicle performance data extracted from the user manuals to estimate the delivery mass of an Ariane 5 ES and a Soyuz launcher, both operating from Centre Spatial Guyanais (CSG), as representative vehicles. These delivery mass estimates were thereafter used to determine feasible payload masses for each orbit scenario configuration, accounting specifically for propellant, fuel tank, support structure, and electric propulsion system mass, the payload mass is thereafter estimated as 20,30 , and $50 \%$ of the remaining mass [35].

Considering first a multiple spacecraft launch scenario, where all required spacecraft are launched on a single vehicle, it is found that a Soyuz cannot provide the required payload mass to any of the orbits considered to enable flight of the instrument concepts detailed in Table 5. However, as shown in Figure 6 the Ariane 5 ES can deliver either of the instrument concepts detailed in Table 5 to all three orbit scenario configurations detailed in Figure 5, for a five-year mission. However, increasing the mission duration to greater than 7.5 years restricts the orbit options to the 16 hour orbit. The Ariane 5 ES can deliver either of the instrument concepts detailed in Table 5 to the 16 hour orbit for mission durations in excess of 10 years. Note that the FCI on-board the Meteosat Third Generation platforms has a design life of 8.5 years, with the possibility to extend the platform life to 11 years [36]; similar lifetimes would therefore be expected of an operational GEO-like polar system.

Considering the launch of a single spacecraft on either of the launch vehicles, as shown in Figure 7 it is found that the use of either instrument concept detailed in Table 5 for a meaningful mission duration (that is $\geq 5$ years) would be challenging on the 12 hour orbit from a Soyuz vehicle. However, this challenge is lessened if the 10 hour orbit is used. The Soyuz vehicle can support either of the instrument concepts detailed in Table 5 on the 16 hour orbit for mission durations of 8.5 - 10 years; longer mission durations may be feasible with appropriate system design optimisation.

\section{CONCLUSIONS}

The main objectives of a Geostationary-like (GEO-like) polar platform would be the cryosphere, geophysical data products and numerical weather prediction at polar and sub-polar regions. The products that would benefit from a GEOlike polar platform are mainly estimated from radiances in the visible/near infrared, and the thermal part of the electromagnetic spectrum, which is consistent with currently proven technologies from Geostationary orbits. Data users, who foresee a potentially increased challenge when continuity of imagery requires use of composite images from different platform locations, consider the use of non-composited images advantageous. Users also find the placement of apogee over the pole to be useful, and largely do not foresee orbit eccentricity and progression of view zenith angle is a barrier to applications. As such, a clear majority of data users find the Taranis orbit concept to be either much or marginally better than a critical inclination orbit (e.g. Molniya concept) due to the improved perspective offered. An eight or four channel imager, with Flexible Combined Imager heritage, would require a mass allocation of $251 \mathrm{~kg}$ or $200 \mathrm{~kg}$, including mass margin, respectively. The eight-channel concept (reflectance and thermal channels) is compliant with all of the identified observation requirements, whereas the four-channel concept (reflectance channels only) is compliant with only a subset of these. A 16 hour, low-radiation orbit offers significant mission lifetimes; however, such an orbit requires an additional spacecraft when compared against 10 and 12 hour orbits; four verses three. An operational system, offering $>10$ years' continuous polar coverage in eight spectral channels could, mostly likely, be deployed from an Ariane 5 ES launch to the 16-hour orbit. A proof-of-concept single spacecraft mission could be deployed from a Soyuz launch to a similar orbit, offering $>10$ years' polar coverage in four spectral channels, or more than five years of coverage in eight spectral channels. 


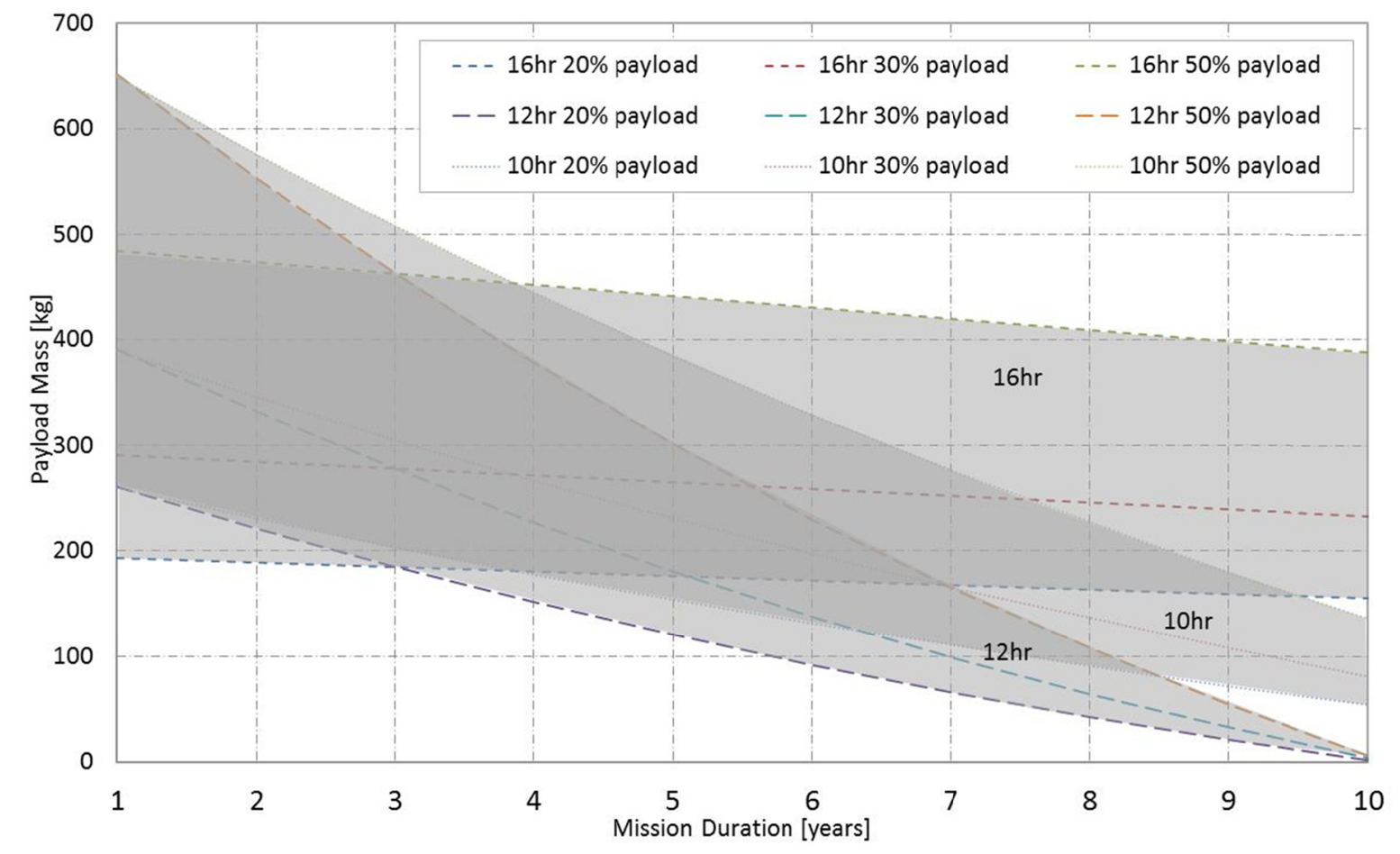

Figure 6. Payload mass allocation over a range of mission lifetimes for 10, 12 and 16 hour orbits for a multiple spacecraft launch from the Ariane 5 ES launcher

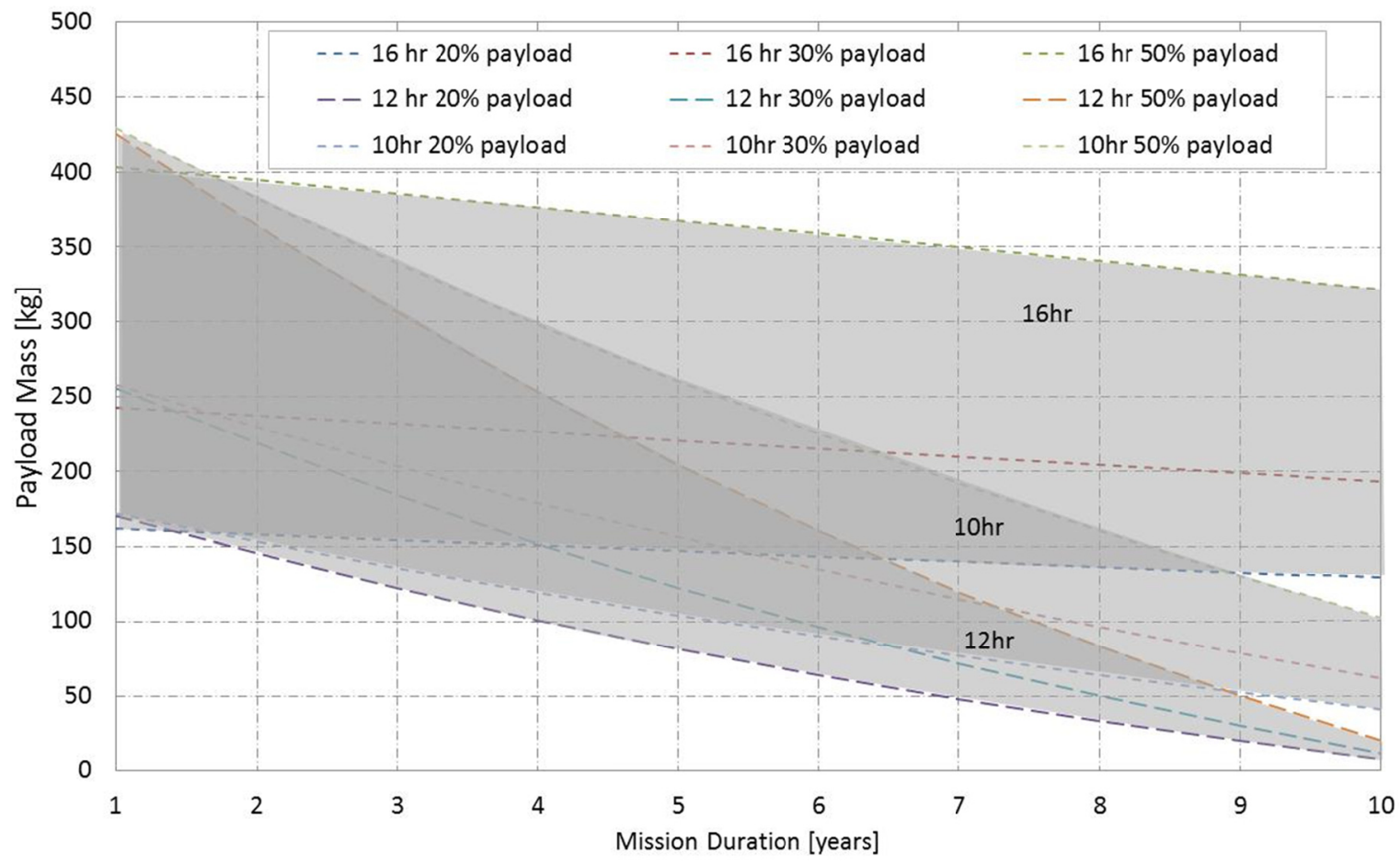

Figure 7. Payload mass allocation over a range of mission lifetimes for 10, 12 and 16 hour orbits for a single spacecraft launch from the Soyuz launcher 


\section{ACKNOWLEDGEMENTS}

The work summarised in this paper was funded by the European Space Agency (ESA) under the contract 'Mission Concepts for a Polar Observation System - ESA Contract Number 4000110268/14/NL/FF/lf.

\section{REFERENCES}

[1] Jeffries, M. O., Richter-Menge, J. A. \& Overland, J. E., editors, "Arctic Report Card," 2013. (Available from: http://www.arctic.noaa.gov/reportcard/ [cited 18 January 2014])

[2] Jaeger, E. B. \& Seneviratne, S. I., "Impact of soil moisture-atmosphere coupling on European climate extremes and trends in a regional climate model," Climate Dynamics, Vol. 36, No. 9-10, April 2010, pp.1919-1939. (doi:10.1007/s00382-010-0780-8) (ISSN 0930-7575)

[3] Matsumura, S. \& Yamazaki, K., "Eurasian Subarctic Summer Climate in Response to Anomalous Snow Cover," Journal of Climate, Vol. 25, No. 4, February 2012, pp.1305-1317. (doi:10.1175/2011JCLI4116.1) (ISSN 0894-8755)

[4] Francis, J. A. \& Vavrus, S. J., "Evidence linking Arctic amplification to extreme weather in mid-latitudes," Geophysical Research Letters, Vol. 39, No. 6, March 2012, p.L06801. (doi:10.1029/2012GL051000) (ISSN 00948276)

[5] Overland, J. E., Francis, J. A., Hanna, E. \& Wang, M., "The recent shift in early summer Arctic atmospheric circulation," Geophysical Research Letters, Vol. 39, No. 6, October 2012, p.L19804. (doi:10.1029/2012GL053268) (ISSN 00948276)

[6] Tang, Q., Zhang, X., Yang, X. \& Francis, J. A., "Cold winter extremes in northern continents linked to Arctic sea ice loss," Environmental Research Letters, Vol. 8, No. 1, March 2013, p.014036. (doi:10.1088/1748-9326/8/1/014036) (ISSN 1748-9326)

[7] Tang, Q., Zhang, X. \& Francis, J. A., "Extreme summer weather in northern mid-latitudes linked to a vanishing cryosphere," Nature Climate Change, Vol. 4, No. 1, December 2013, pp.45-50. (doi:10.1038/nclimate2065) (ISSN 1758-678X)

[8] "Systematic Observation Requirements for Satellite-based Products for Climate Supplemental details to the satellitebased component of the Implementation Plan for the Global Observing System for Climate in Support of the UNFCCC," Global Climate Observing System, GCOS-154, Geneva, Switzerland, December 2011.

[9] Anderson, P. \& Macdonald, M., "Sun-Synchronous Highly Elliptical Orbits Using Low-Thrust Propulsion,” Journal of Guidance, Control, and Dynamics, Vol. 36, No. 6, November 2013, pp.1849-1855. (doi:10.2514/1.59848) (ISSN 0731-5090)

[10] Anderson, P. \& Macdonald, M., "Extension of Highly Elliptical Earth Orbits Using Continuous Low-Thrust Propulsion," Journal of Guidance, Control, and Dynamics, Vol. 36, No. 1, January 2013, pp.282-292. (doi:10.2514/1.55304) (ISSN 0731-5090)

[11] Anderson, P. \& Macdonald, M., "Static, Highly Elliptical Orbits Using Hybrid Low-Thrust Propulsion," Journal of Guidance, Control, and Dynamics, Vol. 36, No. 3, May 2013, pp.870-880. (doi:10.2514/1.56636) (ISSN 0731-5090)

[12] Anderson, P. \& Macdonald, M., "Static Highly Elliptical Orbits Using Hybrid Low-Thrust Propulsion," In Advances in the Astronautical Sciences, (eds J. McAdams D. McKinley M. Berry \& K. Jenkins) Vol. 143, No. 1-3, pp.23052324, Univelt Inc, 2012. (ISSN 1081-6003)

[13] Macdonald, M., Anderson, P. \& Warren, C., “A novel design concept for space-based polar remote sensing," In Proceedings of SPIE, (eds R. Meynart S. P. Neeck \& H. Shimoda) Vol. 8533, SPIE, Edinburgh, Scotland, November 19, 2012. (doi:10.1117/12.971437) (ISSN 0277-786X)

[14] Lubin, D., Ayres, G. \& Hart, S., "Remote Sensing of Polar Regions," Bulletin of the American Meteorological Society, Vol. 90, No. 6, June 2009, pp.825-835. (doi:10.1175/2008BAMS2596.1) (ISSN 0003-0007)

[15] Steffen, K., "The melt anomaly of 2002 on the Greenland Ice Sheet from active and passive microwave satellite observations," Geophysical Research Letters, Vol. 31, No. 20, 2004, p.L20402. (doi:10.1029/2004GL020444) (ISSN 0094-8276)

[16] Belchansky, G. I., "Spatial and temporal multiyear sea ice distributions in the Arctic: A neural network analysis of SSM/I data, 1988-2001," Journal of Geophysical Research, Vol. 109, No. C10, October 2004, p.C10017. (doi:10.1029/2004JC002388) (ISSN 0148-0227)

[17] Derrien, M. \& Le Gléau, H., "Improvement of cloud detection near sunrise and sunset by temporal-differencing and region-growing techniques with real-time SEVIRI," International Journal of Remote Sensing, Vol. 31, No. 7, April 2010, pp.1765-1780. (doi:10.1080/01431160902926632) (ISSN 0143-1161) 
[18] Baker, W. E. et al., "Lidar-Measured Wind Profiles: The Missing Link in the Global Observing System," Bulletin of the American Meteorological Society, Vol. 95, No. 4, April 2014, pp.543-564. (doi:10.1175/BAMS-D-12-00164.1) (ISSN 0003-0007)

[19] Santek, D., “The Impact of Satellite-Derived Polar Winds on Lower-Latitude Forecasts," Monthly Weather Review, Vol. 138, No. 1, January 2010, pp.123-139. (doi:10.1175/2009MWR2862.1) (ISSN 0027-0644)

[20] Lazzara, M. A., Dworak, R., Santek, D. A., Hoover, B. T., Velden, C. S. \& Key, J. R., "High-Latitude Atmospheric Motion Vectors from Composite Satellite Data," Journal of Applied Meteorology and Climatology, Vol. 53, No. 2, February 2014, pp.534-547. (doi:10.1175/JAMC-D-13-0160.1) (ISSN 1558-8424)

[21] Heygster, G. et al., "Remote sensing of sea ice: advances during the DAMOCLES project," The Cryosphere, Vol. 6, No. 6, December 2012, pp.1411-1434. (doi:10.5194/tc-6-1411-2012) (ISSN 1994-0424)

[22] Schröder, D., Feltham, D. L., Flocco, D. \& Tsamados, M., "September Arctic sea-ice minimum predicted by spring melt-pond fraction," Nature Climate Change, Vol. 4, No. 5, April 2014, pp.353-357. (doi:10.1038/nclimate2203) (ISSN 1758-678X)

[23] Merchant, C. J. et al., "A 20 year independent record of sea surface temperature for climate from Along-Track Scanning Radiometers," Journal of Geophysical Research, Vol. 117, No. C12, December 2012, C12013. (doi:10.1029/2012JC008400) (ISSN 0148-0227)

[24] Merchant, C. J., Le Borgne, P., Roquet, H. \& Legendre, G., "Extended optimal estimation techniques for sea surface temperature from the Spinning Enhanced Visible and Infra-Red Imager (SEVIRI)," Remote Sensing of Environment, Vol. 131, April 2013, pp.287-297. (doi:10.1016/j.rse.2012.12.019) (ISSN 00344257)

[25] Key, J. R., Collins, J. B., Fowler, C. \& Stone, R. S., "High-latitude surface temperature estimates from thermal satellite data," Remote Sensing of Environment, Vol. 61, No. 2, August 1997, pp.302-309. (doi:10.1016/S00344257(97)89497-7) (ISSN 00344257)

[26] Eastwood, S., Le Borgne, P., Péré, S. \& Poulter, D., "Diurnal variability in sea surface temperature in the Arctic," Remote Sensing of Environment, Vol. 115, No. 10, October 2011, pp.2594-2602. (doi:10.1016/j.rse.2011.05.015) (ISSN 00344257)

[27] Williamson, S., Hik, D., Gamon, J., Kavanaugh, J. \& Flowers, G., "Estimating Temperature Fields from MODIS Land Surface Temperature and Air Temperature Observations in a Sub-Arctic Alpine Environment," Remote Sensing, Vol. 6, No. 2, January 2014, pp.946-963. (doi:10.3390/rs6020946) (ISSN 2072-4292)

[28] Laszlo, I., Ciren, P., Liu, H., Kondragunta, S., Tarpley, J. D. \& Goldberg, M. D., "Remote sensing of aerosol and radiation from geostationary satellites," Advances in Space Research, Vol. 41, No. 11, January 2008, pp.1882-1893. (doi:10.1016/j.asr.2007.06.047) (ISSN 02731177)

[29] Mei, L., Xue, Y., de Leeuw, G., von Hoyningen-Huene, W., Kokhanovsky, A. A., Istomina, L., Guang, J. \& Burrows, J. P., "Aerosol optical depth retrieval in the Arctic region using MODIS data over snow," Remote Sensing of Environment, Vol. 128, January 2013, pp.234-245. (doi:10.1016/j.rse.2012.10.009) (ISSN 00344257)

[30] Istomina, L. G., Hoyningen-Huene, W. V., Kokhanovsky, A. A., Schultz, E. \& Burrows, J. P., "Remote sensing of aerosols over snow using infrared AATSR observations," Atmospheric Measurement Techniques Discussions, Vol. 4, No. 1, 2011, pp.33-71. (doi:10.5194/amtd-4-33-2011) (ISSN 1867-8610)

[31] Schröder, M., Roca, R., Picon, L., Kniffka, A. \& Brogniez, H., "Climatology of free tropospheric humidity: extension into the SEVIRI era, evaluation and exemplary analysis," Atmospheric Chemistry and Physics Discussions, Vol. 14, No. 7, April 2014, pp.9603-9646. (doi:10.5194/acpd-14-9603-2014) (ISSN 1680-7375)

[32] Laupattarakasem, P., Jones, W. L., Hennon, C. C., Allard, J. R., Harless, A. R. \& Black, P. G., "Improved Hurricane Ocean Vector Winds Using SeaWinds Active/Passive Retrievals," IEEE Transactions on Geoscience and Remote Sensing, Vol. 48, No. 7, July 2010, pp.2909-2923. (doi:10.1109/TGRS.2010.2043110) (ISSN 0196-2892)

[33] Krijger, J. M., van Weele, M., Aben, I. \& Frey, R., "Technical Note: The effect of sensor resolution on the number of cloud-free observations from space," Atmospheric Chemistry and Physics, Vol. 7, No. 11, June 2007, pp.2881-2891. (doi:10.5194/acp-7-2881-2007) (ISSN 1680-7324)

[34] Gorlani, M., Tosetto, A., Tentoni, L., Perotto, V. \& Pin, O., “A Tool for Flexible and Rapid Thermal Analysis and Design in Feasibility and Preliminary Phases of Space Projects," Society of Automotive Engineers, 2005-01-3053, New York City, USA, July 2005. (doi:10.4271/2005-01-3053)

[35] Larson, W. \& Wertz, J., editors, "Space Mission Analysis and Design, Microcosm," Third. Microcosm, 1999 (ISBN: 9781881883104)

[36] Aminou, D. M., Lammarre, D., Stark, H. ., van den Braembussche, P., Blythe, P., Fowler, G., Gigli, S., Stuhlmann, R. \& Rota, S., "Meteosat Third Generation (MTG) status of space segment definition," In Proceedings of SPIE, (eds R. Meynart S. P. Neeck \& H. Shimoda) Vol. 7474, SPIE, September 2009. (doi:10.1117/12.830969) (ISSN 0277-786X) 